\title{
Three Revolutions of the Modern Era
}

\author{
Richard A. Easterlin ${ }^{1}$
}

Published online: 11 June 2019

(c) The Author(s) 2019

\begin{abstract}
The emergence and evolution of modern science since the seventeenth century has led to three major breakthroughs in the human condition. The first, the Industrial Revolution, started in the late eighteenth century and is based chiefly on developments associated with the rise of the natural sciences. The second, the Demographic Revolution, began in the latter half of the nineteenth century and is largely the result of progress in the life sciences. The third is a Happiness Revolution that commenced in the late twentieth century and is the outgrowth of the social sciences. The first two revolutions, both familiar concepts, are summarized briefly; this paper develops the rationale for the third, the Happiness Revolution. It also notes the implications of this perspective for the interpretation of international cross-sectional studies.
\end{abstract}

Keywords Scientific Revolution - Industrial Revolution · Demographic Revolution · Happiness $\cdot$ Cross section

JEL Classification N30 $\cdot$ I31 $\cdot$ I15 $\cdot$ C21

\section{Introduction}

The last three centuries have seen quantum leaps in the human condition. The first was the Industrial Revolution which began in the late eighteenth century; the second, the Demographic Revolution that started in the late nineteenth century; and we are now in the midst of a third, a Happiness Revolution, taking off in the late twentieth century.

This paper starts with a summary of the first two revolutions, noting for each, first, the evidence for a "quantum leap," and then its sources, drawing on Easterlin (1996, 2004). It then turns to the case for a Happiness Revolution. Finally, the

Richard A. Easterlin

easterl@usc.edu

1 University Professor Emeritus of Economics, University of Southern California, Pasadena,

CA 91105, USA 
analysis suggests a new interpretation of international cross sections that compare variables reflecting the different revolutions.

\section{Industrial Revolution}

The Industrial Revolution brought about a marked advance in material living conditions. As an example, the living level in the USA today is more than ten times that which prevailed over two centuries ago. Seen from today's perspective, conditions then were little short of "camping out." In rural areas-which in 1790 accounted for almost all of the nation's population-housing typically consisted of a one story house with one or two rooms, and no flooring except the hard earth. A fireplace with a chimney provided heating and cooking. Toilet facilities consisted of outdoor privies. Water and wood had to be fetched. A few windows with shutters but no glass provided ventilation and daylight; candles supplemented the fireplace for light in the evening. Transportation consisted of a horse and wagon. Compare this with today's panoply of consumer goods-multi-room homes with one or more full bathrooms, electrical appliances and running water, telecommunications and computers, cars and planes, and a phenomenal array of food and clothes - and one gets a hint of what the tenfold multiplication of GDP per capita means in terms of people's substantive lives.

The basis of this manifold growth in living levels was a radical advance in the methods by which goods are produced. Prior to the Industrial Revolution manufacturing was carried on in shops or at home, chiefly with hand tools. Wood was the principal industrial material. The sources of power were human, animal, wind, and water. In the late eighteenth century inventions in steam power and wrought iron laid the foundation for machine methods of production, a general-purpose technology applicable in multiple industries throughout manufacturing, where factories became the principal unit of production, and in transportation, communications, agriculture, and construction. Toward the end of the nineteenth century a second general-purpose production technology was developed that supplemented and, in some cases, replaced the first. This technology was based on a new batch of inventions-electricity, the internal combustion engine, steel, nonferrous metals, and plastics. And today we are experiencing yet another wave of new inventions due to such developments as Internet technology, robotics, and renewable energy. This sequence of widely applicable productivity-raising inventions - unprecedented in human history-has brought about a revolutionary change in the everyday living conditions of the average household.

\section{Demographic Revolution}

The Demographic Revolution is the shift from high to low levels of mortality and fertility that started in the last half of the nineteenth century. In countries that led the way in reducing mortality, life expectancy at birth has more than doubled, from around 40 years to 80 or more. The reduction in mortality was the prime mover in fertility 
decline. Before the sharp decrease in mortality only about one out of three births was likely to survive to adulthood; today, the proportion surviving is over $98 \%$. With such an improvement in infant and, along with it, child mortality, parents increasingly found themselves with more surviving children than they wanted and were induced to control their childbearing. Initially, the decline in fertility was accomplished by traditional methods of birth control such as withdrawal, but in the latter half of the twentieth century new techniques were introduced, like the IUD and birth control pills. In the countries leading the Demographic Revolution the average number of births per woman has dropped from five or more to two or less today.

The Demographic Revolution, like the Industrial Revolution, was driven by a continuing flow of advances in technology, but this time in a quite different area, the control of communicable disease. Before the mid-nineteenth century there was very little useful knowledge of the causes, transmission, or treatment of disease. An example is the medical care of a Philadelphia tallow chandler in the fall of 1826,

who complained of chills, pains in the head and back, weakness in the joints and nausea.... [B]efore seeing a regular physician he was bled till symptoms of fainting came on. Took an emetic, which operated well. For several days after, kept his bowels moved with Sulph. Soda, Senna tea, etc. He then employed a Physician who prescribed another Emetic, which operated violently and whose action was kept up by drinking bitter tea. (Rosenberg 1979, 13)

One may reasonably wonder about the value of the main treatments for disease prior to the Demographic Revolution-emetics, cathartics, diuretics, and bleeding. It is quite likely that the economists' "health production function" at that time had a negative input-output relationship, and that economic growth, by increasing the risk of disease via urban crowding, exposed an increasing proportion of the population to risk of death.

The biomedical developments that were eventually to bring infectious disease under control took three principal forms. The first, starting with the sanitation revolution around the mid-nineteenth century, consisted of new methods to prevent the transmission of disease, based on discoveries of the carriers of infection-contaminated air and water, insects, and rodents. The second, which began in the late nineteenth century, was the development of vaccines to prevent diseases like diphtheria, pertussis, tetanus, and yellow fever. The third, dating from the 1930s, was the discovery of antimicrobials that could be used to cure infectious disease.

Today, the attention of medical research has increasingly shifted from infectious disease to conditions of older age, and significant advances have been made in reducing deaths from heart disease and stroke. These improvements are due principally to a decline in cigarette smoking, developments in the treatment and control of high blood pressure and high cholesterol, and new advances in coronary surgery. 


\section{Timing and Geographic Diffusion}

The Demographic Revolution lagged the Industrial Revolution by over half a century, but the way in which each spread throughout the world was quite similar. In broad outline, both start in Western Europe and spread southward and eastward across the face of Europe. A roughly concurrent expansion takes place in overseas offshoots of Europe, places where migrants settled in substantial numbers-Northern America, parts of Latin America, and Oceania. Next come the Third World countries in Asia, the rest of Latin America, and Northern Africa, and, finally, Sub-Saharan Africa. Although the Demographic Revolution lagged the Industrial Revolution, it spread much more rapidly and in Sub-Saharan Africa has preceded the Industrial Revolution. Proponents of the view that economic growth is the cause of the Demographic Revolution, as suggested by a cross section of life expectancy against GDP per capita, are hard put to explain why in Western Europe the Demographic Revolution lagged the Industrial Revolution by half a century or more, but occurred in Sub-Saharan Africa before the onset of the Industrial Revolution.

To say that the Industrial and Demographic Revolutions spread in similar ways throughout the world does not mean that their patterns of geographic diffusion were identical. The order of individual countries varied depending on the extent to which their circumstances at the time were conducive to adopting the technology of a given revolution. But by and large the geographic spread was similar because Western Europe and, in time, its offshoots, were the principal source of the new knowledge, and its adoption elsewhere was constrained, among other things, by fairly well-established country differences in institutions and what today would be called STEM resources (Science, Technology, Engineering, and Mathematics). For follower countries to overtake and pass Western Europe and its offshoots would have required catching up and surpassing them in the ongoing expansion of scientific knowledge.

\section{Scientific Revolution}

The magnitude and rapidity of the advances in the Industrial and Demographic Revolutions are unparalleled in historical experience. Their occurrence was due at bottom to the emergence and growth of empirically tested scientific knowledge in Western Europe and its offshoots. Before the seventeenth century the fields of science as we know them today did not exist, and inquiries into the physical world fell under the heading of "natural philosophy." The term "scientist" did not appear until the nineteenth century.

The seventeenth century saw the onset in Western Europe of the Scientific Revolution, a transformation in the method of discovering knowledge from a priori deduction to an empirical and experimental approach. In effect, scholars ascertained the techniques by which one discovers scientific knowledge (Mokyr 
2005). The first scientific fields to emerge were in the natural sciences-astronomy and physics in the sixteenth and seventeenth centuries, followed by chemistry in the eighteenth, and electricity and thermodynamics in the nineteenth century. Developments in these fields went hand-in-hand with the inventions that fueled the Industrial Revolution, with cause and effect going in both directions. Both the scientific discoveries and inventions were the product of the new methods of inquiry of the Scientific Revolution.

Life sciences like biology — those concerned with the study of living organismsdid not take off until the nineteenth century. These sciences developed in close association with the public health and medical advances of that era and were responsible for the Demographic Revolution. It is the later emergence of the life sciences compared with the natural sciences that explains why the Demographic Revolution lagged the Industrial Revolution. Yet the Demographic Revolution spread throughout the world much more rapidly, mainly because of the relatively low cost of controlling infectious disease compared to that of accelerating economic growth.

\section{The Happiness Revolution}

The Happiness Revolution consists of a marked improvement in people's feelings of well-being, i.e., their subjective well-being. Whereas the two prior revolutions are embodied in markers of people's objective circumstances, real GDP per capita and life expectancy, the principal measure of the Happiness Revolution is people's selfreported feelings about their lives as a whole, captured in survey questions about their overall happiness, satisfaction with life in general, or where they stand on a ladder of life, where the top of the ladder is the best of all possible worlds, and the bottom, the worst. These measures, which are typically on a bounded integer scale, e.g., from zero to ten, give quite similar pictures of cross section and time series patterns of subjective well-being. They are usually referred to collectively as measures of "happiness."

There is now an annual World Happiness Report, produced under the auspices of the United Nations, that presents happiness estimates for over 150 countries worldwide. The geographic differences in happiness are much like those observed for the Industrial and Demographic Revolutions. On a scale from zero to ten, Western European countries and their offshoots are highest with values reaching as high as 7.5 or more and Sub-Saharan African nations lowest, in the range of 3.0-4.0. As an example of what this difference in average happiness means in terms of people's feelings about their lives, in India where mean happiness in 2016-2018 was 4.0, 8.6\% of respondents reported values of 7 or higher; in the top three happiest countries (Finland, Denmark, and Norway), the percentage reporting 7 or more was almost ten times higher, $85 \%$.

The basis of the Happiness Revolution is the development of the social sciences. The first and foremost achievement of the social sciences has been to establish widespread public recognition that circumstances like unemployment, poor health, and poverty are the result chiefly of forces beyond an individual's control, and that collective action is required to help those suffering from such circumstances. Prior to 
the twentieth century, the common belief was that these problems were the result of an individual's character flaws-laziness, failure to save, dirtiness, drunkenness, gambling, and the like. Economics, the first of the social sciences to develop, initially supported such beliefs through its advocacy of laissez-faire, that government should be small and that to intervene in people's lives would only promote dependency. The laissez-faire conception was increasingly undermined, however, by the persistence of grinding poverty and the emergence of severe financial crises and major depressions.

As the problems of the free market economy became clearer, the developing social sciences put forward two major strands of policy solutions. On the economic side were policies aimed at stabilizing the economy at high levels of employmentfirst, via the establishment in the early twentieth century of central banks, responsible for monetary policy, and then, in response to the Great Depression of the 1930s, fiscal policy, the anti-cyclical use of government taxing and spending. Around the same time, social policy started to take shape, eventuating in policies comprising what is now called the "social safety net." This consists of programs encompassing such things as income support (unemployment insurance, social security, social assistance, and disability benefits), health care, infant and childcare, education including preschool programs, maternity and paternity leave, elderly care, and oldage pensions. These economic and social policy initiatives, which are still evolving, are most fully realized in today's welfare state. The cradle-to-grave safety net of the welfare state addresses the concerns most important, according to national surveys, for personal happiness over the life course-employment and income security, a fulfilling family life, and good health. The extent of a nation's success in addressing these concerns is captured in measures of happiness-hence the "Happiness Revolution."

In the past half-century, the social science study of self-reported happiness has taken off, and happiness has begun to nudge aside GDP per capita as a measure of social progress (Clark 2018; Easterlin 2010; Oswald 1997). It may seem soon to speak of a Happiness Revolution, but there is good reason, because happiness, unlike GDP, captures in more comprehensive fashion the varied contributions the social sciences are making to advancing personal well-being. The Nordic countries, who have been in the forefront of introducing and developing welfare state policies, are consistently the world leaders. Especially noteworthy is the fact that less-advantaged segments of the population in these countries benefit particularly from safety net policies. As a result, the happiness gap between the more- and less-advantaged in the Nordic nations is small compared with the worldwide average. Historical data on happiness do not go back far enough to demonstrate the increase in happiness associated with the establishment of safety net policies. But the experience of the countries transitioning from socialism to capitalism in the post-1989 period shows dramatically how happiness decreases when the safety net is dissolved (Easterlin 2010).

A major milestone contributing to the acceptance of measures of happiness was the 2008 Report of the Commission on the Measurement of Economic Performance and Social Progress. This document was the result of the then French President Nicholas Sarkozy's dissatisfaction with GDP as a measure of social progress. 
In February 2008 he asked three economists-Joseph Stiglitz, Amartya Sen (both Nobel Prize winners in economics), and Jean-Paul Fitoussi, to create a commission to consider better ways of measuring social progress. The resulting 25 -member group included twenty-two scholars with advanced degrees in economics and five Nobel Prize winners. Among the Commission's recommendations was the unequivocal endorsement of measures of "subjective well-being":

Research has shown that it is possible to collect meaningful and reliable data on subjective as well as objective well-being....[T]he types of questions that have proved their value within small-scale and unofficial surveys should be included in larger-scale surveys undertaken by official statistical offices.

(Stiglitz et al. 2008, 15)

In keeping with these recommendations are recent developments in policy-making, where measures of happiness are gaining growing application. Whereas GDP focuses on output and is a concept largely confined to the discipline of economics, happiness is a measure recognized and employed by all of the social sciences. As noted, it reflects, not just the production of material goods, but the things universally important for people's lives. A 2013 document issued by the Secretary-General of the United Nations encourages governments to use "carefully constructed regular, large-scale data on happiness and well-being as a more appropriate indicator for improving macroeconomic policymaking and informing service delivery." Uniform guidelines for the official collection of happiness data have been put forth by the European Organization for Economic Cooperation and Development (OECD). The UK has been a leader in collecting happiness data and using it to guide public policy decisions.

The Happiness Revolution may be defined as the implementation via public policies of social science knowledge to improve subjective well-being. A positive crosssectional relationship between happiness and GDP per capita is sometimes cited as demonstrating that economic growth causes greater happiness. It is hard to reconcile this assertion with the fact that Costa Ricans, whose government introduced safety net policies as early as the 1950s, are as happy as Americans despite a GDP per capita only one-fourth as great. It is also hard to square this view with the nil time series relationship between trends in happiness and GDP per capita (Easterlin 2017). In the USA happiness today is no greater than 70 years ago when real GDP per capita was one-third of its current level; in China, life satisfaction in 2015 was about the same as in 1990 despite a roughly fivefold multiplication of real GDP per capita (Easterlin et al. 2017).

\section{International Cross Sections in Historical Perspective}

It has become commonplace in the social sciences to infer causation from international cross sections. In current point-of-time data, for example, countries with higher GDP per capita are typically higher on life expectancy, and those with lower GDP per capita, lower on life expectancy. This positive association is used to argue that economic growth causes an increase in life expectancy, 
that "wealthier is healthier" (Pritchett and Summers 1996, p. 841; cf. Inglehart 1997). Similarly, a positive cross-sectional relation of GDP per capita to happiness is said to reveal that economic growth induces greater happiness (Deaton 2008; Diener and Oishi 2000; Inglehart 2000). This tendency to infer causation from cross sections is especially common in economics, where associations with economic growth, as indexed by real GDP per capita, are used to argue for the widespread beneficence of economic growth. The foregoing suggests an alternative interpretation, that international cross sections that compare variables reflecting different revolutions may be little more than a by-product of historical experience and do not signify important causal relationships between the variables (Easterlin 2012). Similar reasoning may apply to cross-sectional comparisons of regions within countries, where one area is typically found in the leadership and another to lag far behind.

The key to understanding the implications for cross-sectional analysis of historical experience is that all three revolutions mainly follow the same pattern of geographic diffusion. They originate in Western Europe, the birthplace of the Scientific Revolution and its technological offspring, and come last to Sub-Saharan Africa. As a result, the countries of Western Europe currently tend to be high on GDP per capita, life expectancy, and happiness, while those in Sub-Saharan Africa are low on all three. Thus, when we observe a positive cross-sectional association between life expectancy and GDP per capita, or between happiness and GDP per capita, we are learning, not about causal relationships, but chiefly that Western Europe has been the leader in each magnitude's improvement, and that these breakthroughs have spread to other parts of the world in similar fashion, coming last to Sub-Saharan Africa. The cross-sectional patterns are, at bottom, the by-product of the similar paths of geographic diffusion of the three revolutions. They are the fruit of history-registering the way in which scientific knowledge and its application has evolved and spread throughout the world.

To illustrate schematically, consider just Western Europe and Sub-Saharan Africa, omitting the other geographic areas, partly for simplicity and partly because correlation statistics are especially affected by extreme values. Suppose that the Industrial Revolution starts in 1800 in Western Europe, but not until 1990 in Sub-Saharan Africa. Western Europe's long head start means that in 2020 its GDP per capita is much higher than that of Sub-Saharan Africa (Fig. 1a). Next, let the Demographic Revolution start in Western Europe around 1880 and in Sub-Saharan Africa in 1970. Again, Western Europe's leadership means that its life expectancy in 2020 is considerably greater than that in SubSaharan Africa (Fig. 1b). If a 2020 cross section of life expectancy against GDP per capita is then plotted, we find Western Europe with considerably higher values than Sub-Saharan Africa on both magnitudes (Fig. 1c). But this does not mean that high GDP per capita caused high life expectancy. What Fig. 1c shows is that Western Europe led Sub-Saharan Africa in the onset and growth of two largely independent magnitudes and consequently has higher current values on each. 
(a) INDUSTRIAL REVOLUTION

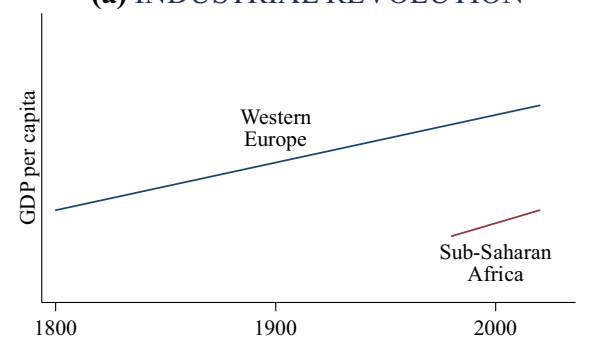

(b) DEMOGRAPHIC REVOLUTION

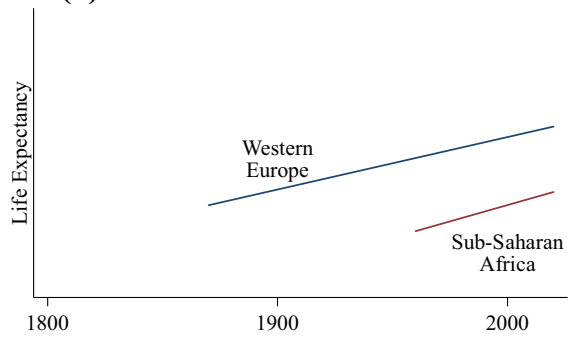

(c) 2020 CROSS SECTION

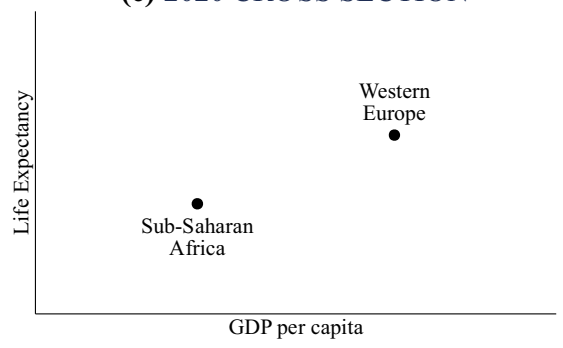

Fig. 1 Schematic illustration: historical background of current cross section between life expectancy and GDP per capita

\section{Conclusion}

Considered in historical perspective, the Industrial Revolution is, at bottom, the product of the natural sciences; the Demographic Revolution, the fruit of the life sciences; and the Happiness Revolution, the creation of the social sciences. Although there is some interdependence, each revolution, based as it is on a distinctive body of knowledge, is largely independent of the others. The sequence in the occurrence of the revolutions reflects the progression in the emergence and growth of knowledge since the Scientific Revolution of the seventeenth centuryfrom natural sciences to life sciences to social sciences. In each area of science, there has been a continuous interplay between basic and applied knowledge; both types of knowledge are products of the scientific method that gave birth to the Scientific Revolution. All three revolutions have followed a quite similar path of diffusion throughout the world, starting in Western Europe and its offshoots and ending in Sub-Saharan Africa.

This view suggests a new interpretation of international cross sections that combine variables reflecting the different revolutions. A significant international crosssectional relationship may be due, not to a causal connection between the variables, but simply to the variables following a similar path of geographic spread over time, as has been illustrated here in regard to GDP per capita, life expectancy, and happiness. The lesson is that each variable in an international cross section needs to be examined in terms of the historical conditions that led to its current magnitude and spatial pattern. Ignorance of history is no excuse. 
Acknowledgements This paper has benefitted greatly from contributions by J. H. Helliwell, Kelsey O'Connor, the editor of this journal, the paper's referees, and, most of all, Andrew Oswald.

Open Access This article is distributed under the terms of the Creative Commons Attribution 4.0 International License (http://creativecommons.org/licenses/by/4.0/), which permits unrestricted use, distribution, and reproduction in any medium, provided you give appropriate credit to the original author(s) and the source, provide a link to the Creative Commons license, and indicate if changes were made.

\section{References}

Clark, A.E. 2018. Four Decades of the Economics of Happiness: Where Next? Review of Income and Wealth 64 (2): 245-269.

Deaton, A. 2008. Income, Health, and Well-Being Around the World: Evidence from the Gallup World Poll. Journal of Economic Perspectives 22 (2): 53-72.

Diener, E., and S. Oishi. 2000. Money and Happiness: Income and Subjective Well-Being Across Nations. In Culture and Subjective Well-Being, ed. E. Diener and E.M. Suh, 185-218. Cambridge Massachusetts: MIT Press.

Easterlin, R.A. 1996. Growth Triumphant: The Twenty-first Century in Historical Perspective. Ann Arbor, Michigan: The University of Michigan Press.

Easterlin, R.A. 2004. The Reluctant Economist: Perspectives on Economics, Economic History, and Demography. New York: Cambridge University Press.

Easterlin, R.A. 2010. Happiness, Growth, and the Life Cycle. Oxford: Oxford University Press.

Easterlin, R.A. 2012. Cross Sections are History. Population and Development Review 38 (Supplement): 302-308.

Easterlin, R.A. 2017. Paradox Lost? Review of Behavioral Economics 4 (4): 311-339.

Easterlin, R.A., F. Wang, and S. Wang. 2017. Growth and Happiness in China. In World Happiness Report 2017, ed. J.F. Helliwell, R. Layard, and J. Sachs, 48-83. New York: Sustainable Development Solutions Network.

Inglehart, R. 1997. Modernization and Post-modernization: Cultural, Economic, and Political Change in 43 Societies. Princeton, New Jersey: Princeton University Press.

Inglehart, R. 2000. Globalization and Postmodern Values. Washington Quarterly 23 (1): 215-228.

Mokyr, J. 2005. The Intellectual Origins of Modern Economic Growth. Journal of Economic History 65 (2): 285-351.

Oswald, A.J. 1997. Happiness and Economic Performance. Economic Journal 107 (445): 1815-1831.

Pritchett, L., and L.H. Summers. 1996. Wealthier is Healthier. Journal of Human Resources XXXI (4): $841-868$.

Rosenberg, C.E. 1979. The Therapeutic Revolution: Medicine, Meaning, and Social Change in Nineteenth-Century America. In The Therapeutic Revolution, Chapter 1, ed. M.J. Vogel and C.E. Rosenberg. Philadelphia: University of Pennsylvania Press.

Stiglitz, J.E., A. Sen, and J.P. Fitoussi. 2008. Report of the Commission on the Measurement of Economic Performance and Social Progress. http://www.stiglitzsen-fitoussi.fr.

Publisher's Note Springer Nature remains neutral with regard to jurisdictional claims in published maps and institutional affiliations. 